Jurnal HELPER, Vol 37 No 2 (2020) 09 - 16

Bimbingan dan Konseling Universitas PGRI Adi Buana Surabaya

ISSN: 02162938

\title{
MENURUNKAN RENDAH DIRI SISWA MELALUI \\ KONSELING KELOMPOK DENGAN STRATEGI COGNITIVE RESTRUCTURING
}

\author{
Dwi Ridhowati \\ SMP Negeri 2 Merakurak-Tuban \\ dwiridhowati@gmail.com \\ Winda Nur Hidayanti \\ SMA Negeri 1 Tongas \\ yasnda@gmail.com \\ Eva Yuanita Ferdian \\ SMK Negeri 2 Bagor \\ agfaaflah09@gmail.com \\ Anita Dianasari, S.Pd. \\ SMK Negeri 1 Kemlagi \\ anitadianasari@gmail.com \\ Kusumaningtyas Febri Wijayanti
SMK PGRI 2 Jombang
kusumaningtyas05@gmail.com
}

\begin{abstract}
Abstrak
Tujuan penelitian ini adalah untuk menguji efektivitas Menurunkan rendah diri melalui konseling kelompok cognitife restrukturing siswa kelas VIII-A SMP Negeri 2 Merakurak. Penelitian ini termasuk jenis pretest posttes one group design. Alat pengumpul data yang digunakan adalah angket. Subjek dalam penelitian ini adalah delapan siswa kelas VIII-A yang memiliki rendah diri tinggi. Teknik analisis data yang digunakan adalah statistik non parametik dengan uji Wilcoxon dengan taraf signifikan 5\%, menunjukan adanya perbedaan skor tingkat rendah diri sebelum dan sesudah penerapan konseling kelompok cognitive restructuring. Hal ini berarti bahwa rendah diridapat diturunkan melalui konseling kelompok dengan strategi cognitive restructuring. Jadi hipotesis yang diajukan dalam peneliytian ini yang berbunyi "Rendah diri siswa secara signifikan dapat ditingkatkan melalui konseling kelompok dengan strategi cognitive restructuring pada siswa kelas VIII-A SMP Negeri 2 Merakurak-Tuban Tahun Pelajaran 2020/2021" dapat diterima.

Kata kunci: Strategi cognitive restructuring, rendah diri siswa
\end{abstract}




\begin{abstract}
The puspose of this research was to test the effectiveness of reducing low self esteem through cognitive restructuring group counseling of class VIII-A students SMPN II Merakurak. This research is a pretest-posttes one group design. Tha date collection tool used was a questionnaire. The subject in this reasearch were eigth studentsof class VII-A who had non-parametric statistics using the wilcoxon test with a significant level of 5\%, indicating a difference in the low self-esteem scores before and after the implementation of restructuring cognitive group counseling. This means that low self-esteem can be reduced through the counseling of restructuring cognitive group. So the hypothesisi put forward in this research which reads "The low self-esteem of students can be significantly improved through group counseling with cognitive restructuring strategies in class VIII-A student of SMP Negeri 2 Merakurak-Tuban for the 2020/2021 academic year" acceptable
\end{abstract}

Keyword: cognitife restructuring strategy, low-esteem students

\section{LATAR BELAKANG}

Rendah diri adalah suatu perasaan dimana seseorang merasa lebih rendah dibanding orang lain. Rasa rendah diri sangat mengganggu, Seperti yang sudah dijabarkan di atas, individu menjadi menarik diri dari lingkungan, merasa canggung bila bertemu dengan orang lain, serta malu mengungkapkan pendapat di muka umum. Hal tersebut tentu menghambat proses perkembangan individu, apalagi jika individu tersebut masih dalam usia remaja, yang mana masa remaja, seperti yang telah disebutkan, adalah masa 'badai dan tekanan'.

Hal tersebut juga terjadi pada siswa SMPN 2 Merakurak-Tuban. Berdasarkan pengamatan kami, ditemukan beberapa siswa kelas VIII-A yang memiliki rasa rendah diri. Dari hasil analisis tes MPCL yang pernah kami laksanakan diketahui topik permasalahan yang paling tinggi presentasenya adalah topik permasalahan pribadi

Pihak sekolah terutama konselor sekolah telah melakukan usaha untuk mengatasi permasalahan ini. Pemberian layanan informasi, bimbingan, maupun konseling kelompok yang pernah dilakukan diharapkan mampu mengurangi rasa rendah diri yang dialami oleh siswa. Dalam layanan informasi terdapat beberapa materi tentang komunikasi, hubungan sosial, dan lain sebagainya.

Melihat fakta ini, kami tertarik untuk melakukan penelitian untuk mereduksi permasalahan tersebut. Kami tertarik untuk menggunakan suatu layanan konseling yang belum pernah digunakan oleh pihak sekolah dan tim kami. Salah satu layanan yang belum pernah digunakan oleh sekolah dan dapat digunakan untuk mengatasi hal ini adalah layanan konseling kelompok cognitif restrukturing 
Jurnal HELPER, Vol 37 No 2 (2020) 09 - 16

Bimbingan dan Konseling Universitas PGRI Adi Buana Surabaya

ISSN: 02162938

Konseling kelompok cognitive restructuring merupakan suatu layanan dalam bimbingan konseling yang diberikan kepada sekelompok siswa/konseli dalam waktu yang bersamaan untuk mengatasi setiap permasalahan anggota kelompok, dengan cara merubah pandangan irasional menjadi rasional. Konseling kelompok cognitif restructuring dapat digunakan memecahkan masalah yang bersumber pada adanya kognisi negatif konseli.

Konseling kelompok cognitif restrukturing cocok digunakan untuk mengatasi permasalahan rendah diri karena seorang yang rendah diri tidak hanya memiliki masalah pada kognitifnya saja, tetapi juga pada emosi serta perilakunya.

Merujuk dari penjelasan di atas, tujuan penelitian ini adalah mengetahui pengaruh penggunaan konseling kelompok dengan strategi cognitif restrukturing untuk mengatasi rasa rendah diri yang ada pada siswa SMPN 2 Merakurak-Tuban Kelas VIII-A.

\section{METODOLOGI PENELITIAN}

Dalam penelitian ini mengunakan pendekatan kuantitatif deskriptif karena berfokus pada angka-angka sebagai suatu alat dalam menganalisis fenomena maupun keterangan di lapangan untuk diketahui yang sebenarnya. Adapun jenis penelitian yaitu pre-eksperimental design karena tujuan dari penelitian ini adalah melihat pengaruh darisuatu perlakuan yang telah diberikan (Purnomo, 2016). Sedangkan menurut Sugiyono (2015) "penelitian yang dengan metode eksperimen dapat dikatakan sebagai suatu cara yang menggunakan perlakuan tertentu dalam melihat seberapa besar pengaruh yang ditimbulkan dalam suatu penelitian, termasuk dalam kondisi apapun dan dengan keadaan yang tidak terkendalikan.”.Maka dari itu, bentuk rancangan penelitian ini menggunakan one group pretest-posstest design. Maksud dari bentuk one group pretestposstest design yaitu, suatu kelompok diberikan tes diawal dan diakhir disamping perlakuan, kelompok tidak adanya kelompok pembanding, pasangan atau diambil secara acak, namun dibentuk suatu kelompok yang sama untuk diberikan perlakuan seterusnya.

Penelitian ini menggunakan populasi peserta didik di kelas VIII-A SMPN 2 Merakurak-Tuban dengan jumlah siswa 30 siswa. Subjek dalam penelitian yaitu terdiri dari 8 orang siswa yang telah dikategorikan berada pada tingkat tinggi rasa rendah diri.

Menurut Sutoyo (Belluano dkk, 2019) angket adalah sejumlah pernyataan yang tertulis tentang fakta, opini serta 
Jurnal HELPER, Vol 37 No 2 (2020) 09 - 16

Bimbingan dan Konseling Universitas PGRI Adi Buana Surabaya

ISSN: 02162938

data faktual yang berkaitan langsung dengan diri responden, yang

perlu dijawab oleh responden untuk mengetahui kebenarannya. Selain itu, untuk mengetahui ada tidaknya perubahan yang signifiikan antara sebelum dan sesudah tindakan tentang rendah diri, yaitu dengan menggunakan teknik analisis data yaitu melalui norma kategori dan SPSS (statistical Product and Service) dengan uji Wilcoxon singned Rank.

\section{HASIL PENELITIAN}

Penelitian ini dilaksanakan telah melewati proses persiapan yang sistematis dan matang. Sebelum memulai penelitian, tahapan awal yang dilakukan adalah menyangkut mengenai pemberian izin penelitian, menyusun instrumen penelitian dan modul eksperimen yaitu sebagai panduan atau petunjuk yang akan digunakan pada saat melaksanakan penelitian dalam melakukan treatment. Pengumpulan data dan penelitian dilakukan kurang lebih yaitu dari tanggal 21 september sampai dengan 20 oktober 2020. Perlakuan (treatment) dilakukan dua belas kali pertemuan (termasuk pretestposttest). Hasil penelitian diperoleh yaitu dengan menggabungkan dua data yang di dapat yakni hasil pretest dan posttest.. Adapun hasil pengumpulan berikut ini:
Gambaran tingkat rendah diri siswa sebelum diberikan treatment konseling kelompok Cognitif restrukturing melalui hasil pretest yang telah diberikan kepada 30 orang siswa. Untuk skor masing-masing siswa yang diambil menjadi peserta yang dijadikan subjek dapat dilihat pada tabel di bawah ini:

Tabel 1.1 Skor Hasil Pre-test

\begin{tabular}{cccc}
\hline No & Inisial & Pretest & Katagori \\
\hline 1 & RF & 86 & Tinggi \\
\hline 2 & FD & 80 & Tinggi \\
\hline 3 & AD & 79 & Tinggi \\
\hline 4 & AM & 77 & Tinggi \\
\hline 5 & HA & 70 & Sedang \\
\hline 6 & SS & 65 & Sedang \\
\hline 7 & AA & 63 & Sedang \\
\hline 8 & MR & 60 & Sedang \\
\hline
\end{tabular}

Pemberian treatment melalui konseling kelompok cognitife restrukturing dilaksanakan selama 12 kali pertemuan (termasuk pretest dan posttest) yang diikuti oleh 8 orang siswa, maka hasil pretest mengenai gambaran rendah diri siswa sesudah diberikan konseling kelompok cognitife restrukturing adalah sebagai berikut ini:

Tabel 1.2 Skor Hasil Post- test

\begin{tabular}{llll}
\hline No & Inisial & Skor & Kategori \\
\hline
\end{tabular}


Jurnal HELPER, Vol 37 No 2 (2020) 09 - 16

Bimbingan dan Konseling Universitas PGRI Adi Buana Surabaya

ISSN: 02162938

\begin{tabular}{cccc}
\hline 1 & RF & 40 & Rendah \\
\hline 2 & FD & 39 & Rendah \\
\hline 3 & AD & 34 & Rendah \\
\hline 4 & AM & 26 & Rendah \\
\hline 5 & HA & 28 & Rendah \\
\hline 6 & SS & 30 & Rendah \\
\hline 7 & AA & 23 & Rendah \\
\hline 8 & MR & 60 & Sedang \\
\hline
\end{tabular}

Perbandingan hasil Pretest-Posttest

Rendah Diri Siswa Sebelum dan

Sesudah diberikan Treatment

Konseling Kelompok Cognitif

Restrukturing.

Berdasarkan hasil pemberian treatment konseling kelompok cognitif restrukturing sebanyak 12 pertemuan (termasuk pretest dan posttest) mengalami perubahan dan penurunan skor rendah diri yang signifikan. Hal tersebut dapat dilihat berdasarkan hasil posttest rendah diri setelah diberikan treatment konseling kelompok cognitif restrukturing yang dibandingkan dengan hasil pretest rendah diri sebelum diberikan treatment konseling kelompok cognitif restrukturing mempunyai perbandingan nilai rata-rata yang sangat signifikan. Perbandingan skor sebelum dan sesudah treatmen dapat dilihat pada tabel dibawah ini:

Tabel 1.3 Perbandingan Pre-test dan Post-test

\begin{tabular}{|c|c|c|c|c|}
\hline $\begin{array}{l}\mathrm{N} \\
\mathrm{O}\end{array}$ & $\begin{array}{l}\text { INISI } \\
\text { AL }\end{array}$ & $\begin{array}{c}\text { PRET } \\
\text { EST }\end{array}$ & $\begin{array}{c}\text { POSTT } \\
\text { EST }\end{array}$ & $\begin{array}{c}\text { PENURU } \\
\text { NAN } \\
\text { SKOR }\end{array}$ \\
\hline 1 & RF & 86 & 40 & 46 \\
\hline 2 & FD & 80 & 39 & 41 \\
\hline 3 & $\mathrm{AD}$ & 79 & 34 & 47 \\
\hline 4 & AM & 77 & 26 & 51 \\
\hline 5 & HA & 70 & 28 & 42 \\
\hline 6 & SS & 65 & 30 & 35 \\
\hline 7 & AA & 63 & 23 & 40 \\
\hline 8 & $\mathrm{MR}$ & 60 & 20 & 40 \\
\hline & $\begin{array}{c}\text { Jumla } \\
\mathrm{h}\end{array}$ & 580 & 240 & 342 \\
\hline & $\begin{array}{l}\text { Rata- } \\
\text { Rata }\end{array}$ & 128,88 & 53,33 & 76 \\
\hline
\end{tabular}

Dari tabel perhitungan perbandingan pretest daan posttest diatas dapat dijelaskan bahwa subjek yang diberikan perlakuan (treatment) mengalami penurunan skor rata-rata adalah 76 , skor rata-rata pretest adalah 128,88 dan setelah diberikan tindakan (treatment) skor pada subjek turun dengan rata-rata skor post-test sebesar 53,33. Penurunan skor paling tinggi dicapai oleh subjek "AM" dengan penurunan sebanyak 51, sedangkan penurunan skor paling sedikit yaitu sebanyak 40 oleh subjek "SS" dan "AA".

Tahapan selanjutnya adalah dengan melakukan uji data yaitu dengan menguji hipotesis penelitian 
Jurnal HELPER, Vol 37 No 2 (2020) 09 - 16

Bimbingan dan Konseling Universitas PGRI Adi Buana Surabaya

ISSN: 02162938

menggunakan rumus Wilxocon Rank Test untuk mencari perbedaan pretest-posttest serta untuk melihat sejauh mana penurunan skor dari keberhasilan penggunaan konseling kelompok cognitif restrukturing untuk menurunkan rendah diri siswa. Jadi, Wilxocon Rank Test merupakan bagian Statistic Nonparametric, karena jumlah sampel dalam penelitian ini yaitu cuma 8 orang siswa, sehingga memiliki data yang tidak normal (Uyanto, 2009). Uji hipotesis menggunakan rumus Wilcoxon Rank Test.

Negative rank atau selisih (negative) antara pre-test dan post-test diberikan treatment strategi cognitif restrukturing adalah 8 data negatif. Artinya pada 8 orang siswa mengalami penurunan skor rendah diri, dari skor pre-test ke post-test. Mean Rank atau rata-rata rangking 4,50 sedangkan jumlah atau Sum Rank adalah 36,00. Postive rank (positive) antara sebelum dan setelah diberikannya treatment untuk pre-test dan post-test adalah 0, baik itu pada nilai N, Mean Rank, maupun Sum Rank,. Nilai 0 menunjukkan tidak adanya peningkatan dari nilai pre-test ke post-tes. Ties merupakan kesamaan nilai pre-test dan post-test. Dari hasil tabel di atas nilai Ties yaitu 0 sehingga dapat dikatakan bahwa tidak adanya nilai yang sama antara pretest dan posttest.
Sedangkan pada pengujian hipotesis dengan uji Wilcoxon rank test, disimpulkan bahwa "Ha" diterima. Maksudnya adalah terdapat perubahan antara sebelum dan setelah diberikannya perlakuan (treatment) konseling kelompok cognitife restrukturing, disimpulkan bahwa "konseling kelompok cognitif restrukturing efektif dapat menurunkan rasa rendah diri siswa" apabila dilihat dari hasil perbandingan sebelum dan sesudah diberikan perlakuan (treatment). Kesimpulan ini mengidentifikasikan bahwa adanya perbedaan atau perubahan rata-rata skor rendah diri sebelum dan sesudah diberikan treatment yang sangat bermakna serta menunjukkan bahwa hipotesis ini berhasil dan sesuai bahwa penggunaan konseling kelompok cognitif restrukturing untuk menurunkan rendah diri siswa. Jadi dapat dikatakan bahwa penggunaan konseling kelompok cognitif restrukturing signifikan dapat menurunkan rendah diri siswa.

\section{KESIMPULAN DAN SARAN}

Berdasarkan uraian hasuil penelitian dan analisis data serta pembahsan hasil sebelum dan sesudah penerapan koseling kelompok dengan strategi cognitif restrukturing untuk menurunkan rendah diri siswa kelas VIII- 
Jurnal HELPER, Vol 37 No 2 (2020) 09 - 16

Bimbingan dan Konseling Universitas PGRI Adi Buana Surabaya

A SMPN 2 Merakurak dapat diuraikan kesimpulannya sebagai berikut: berdasarkan hasil pretest yang diberikan kepada 30 siswa yaitudiperoleh 8 orang siswa dengan skor rat-rata 128,88 yang berada pada kategori rendah diri tinggi dan sedang. Kemudian siswa tersebut diberikan treatment (perlakuan) melalui konseling kelompok cognitif restrukturing. (2) Gambaran dari hasil posttest yaitu setelah diberikan treatment (perlakuan sebanyak 12 kali pertemuan mengalami penurunan yang signifikan, dengan penurunan skor rata-rata 53,33. (3) Secara keseluruhan terdapat perubahan antara sebelum dan sesudah diberikannya treatment (perlakuan), yaitu dengan penurunan skor rata-rata 76 artinya tidak terdapat lagi siswa yang memiliki rendah diri tinggi.

(4) Berdasarkan hasil hipotesis, maka konseling kelompok cognitif restrukturing efektif digunakan untuk menurunkan rendah diri siswa. Hal ini dibuktikan dengan uji statistic membuktikan yaitu nilai rata-rata mean (postest) lebih kecil dari nilai rata-rata mean (pretest), yaitu 53,33 $\leq 128,88$ dari kategori tinggi menjadi kategori rendah dengan perubahan yang positif. Uji Wilxocon juga membuktikan bahwa nilai Asymp.Sig (2-tailed) bernilai 0,012, maka nilai 0,012 lebih kecil < 0,05 maka (Ha) diterima.

Dengan terlaksananya penelitian ini, maka penulis mengajukan saran: Bagi guru BK diharapkan dapat menggunakan konseling kelompok cognitife restrukturing sebagai suatu metode dalam menurunkan rendah diri siswa dan dapat mengembangkan konseling kelompok cognitife restrukturing ini dalam layanan bimbingan konseling. Bagi siswa, di SMPN 2 Merakurak-Tuban telah mengalami penurunan melalui konseling kelompok cognitife restrukturing. Oleh karena itu, disarankan kepada siswa agar penurunan rendah diri yang telah dimiliki dapat dipertahankan dalam kehidupan seharihari. Bagi penelitian selanjutnya, yaitu diharapkan dapat melakukan dengan menggunakan siswa yang berada di daerah selain perkotaan, menambahkan subjek penelitian, dan mempertimbangkan waktu pelaksanaan dengan kondisi yang efisien. Metode penelitian yang digunakan dalam penelitian ini adalah kuantitatif dengan menggunakan skala. Maka selanjutnya bagi peneliti lain dapat menggunakan mixed methods dengan menambahkan penggunaan instrumen seperti wawancara agar hasil penelitian lebih akurat. 
Jurnal HELPER, Vol 37 No 2 (2020) 09 - 16

Bimbingan dan Konseling Universitas PGRI Adi Buana Surabaya

ISSN: 02162938

Sehingga mendapatkan perubahan secara

menyeluruh.

\section{DAFTAR RUJUKAN}

Azwar, Saifudin. 2017. Penyusunnan Skala Psikologi. Yogyakarta: Pustaka Pelajar Offset

Hellraizer. 2002. Kiat Menghadapi

Rendah Diri. (online) (http://forum.kafegaul.com/archi ve/indexPhp/t-70645.html, diakses 20 Juli 2020).

Latipun. 2011. Psikologi Konseling Malang: UPT Penerbitan Muhammadiyah Malang.

Jumadi, S.Pd. Mengatasi Rendah Diri dengan strategi cogniif restructuring pada siswa kelas VII SMPN 1 Genuk Kota Semarang Tahun Pelajaran 2015/2016. Jurnal Pendidikan, (online), (http://edusemar.net/jurnal_pend/e disi1.pdf, diakses 15 Juli 2020).

Sadarjoen, Sawitri. 2016. "Bagaimana Mengatasi Rendah Diri? 'Jakarta: Kompas. 